\title{
The Disc Jockey as Composer, or How I Became a Composing DJ
}

\author{
By Kai Fikentscher
}

Composition ... is the word used in Western culture for centuries to designate the creation of music in general. But the word has been mystified since the nineteenth century, such that it summons up the figure of a semidivine being, struck by holy inspiration, and delivering forth ineffable delphic utterances. Attali's usage returns us to the literal components of the word, which quite simply means 'to put together.' It is this demystified yel humanly dignified activity that Attali wishes to remove from the rigid institutions of specialized musical training in order to return it to all members of society.

\section{-Susan McClary}

Record art is, in brief, a composing of new pieces by means of available recordings.

-DJ Westbam

Only recently and somewhat reluctantly have DJs been accorded some degree of recognition in two musical worlds that rarely impinge upon each other: the music industry and the music academy. In both, DJs tend to be thought of as people who entertain audiences using mediated music, usually vinyl records or CDs, or who work as remixers or record producers by extending the commercial life of a pop song, thereby providing fellow DJs and dancers with music to liven up an evening of clubbing. ${ }^{1}$ Some DJs (DJ Spooky or Christian Marclay, for example) have been critically acclaimed as cultural heroes of the postmodern age, cutting up and mixing various sources into collages of sounds that reflect our time-in which virtually any sound can be heard anywhere, divorced forever from the limitations of time and space. Other DJs (such as Rob Swift and Kid Koala) have abandoned the term "DJ" in favor of "turntablist," presenting the command of a set of turntables and a mixer as comparable to the mastery exhibited by virtuosos of conventional musical instruments. As professionals, some DJs now travel the world and enjoy an audience-appeal comparable to that of earlier or contemporary colleagues who were (or are) pianists, violinists, or guitarists. In the context of hip-hop and house music, deejaying is thought of mainly in terms of performance, which is understandable in view of the many other strands of largely orally transmitted, performance-based, African-American musical forms (such as work songs, hollers, blues, jazz, or gospel). In these forms, as much as in the context of deejaying, the focus 
appears to center primarily on the functional relationship between the music and its performance context. In other words, when performing, matters of time and space are crucial.

In contrast, the term "composition" is rarely encountered in the context of deejaying, perhaps because deejaying does not appear to be about composition in the traditional sense of the word. If we think of composing as an act of musical creation that is primarily concerned with the creation of a final and fixed musical work (i.e., a composition), then deejaying seems to be almost the opposite thereof. Deejaying, after all, involves making music by traveling in reverse. A DJ begins with fixed musical texts (compositions) and alters them in multiple ways, creating his or her unique performance (the mix) by undoing or "de-composing" finished compositions (in most cases, recordings not of one but of many performances mixed together to sound as one).

To speak then of deejaying as composing means to expand upon the traditional definitions of the concept of composing. Precedents for a moreinclusive definition can be found in traditions to which deejaying is conceptually related, where the word 'composition' has been used for quite some time already. In many streams of the African-American musical tradition (such as jazz and blues), where oral transmission is the general rule, the notion of composition has long been a part of the discourse, especially since the discourse of these genres has entered the academy. In contrast to jazz and blues, however, deejaying as performance art has a rather short history. ${ }^{2}$ As a performing musician, the DJ has only recently entered the academic discourse. To refer to a DJ as a composer then may still sound rather odd or unusual to many at the beginning of the new millennium. However, if the history of the discourse of older African-American genres is any indication, this may change in years to come. A little more than half a century ago, who would have thought that music of humble, even controversial, beginnings, such as blues and jazz, would one day be hailed as America's only authentic musical contribution to the world-even as "America's classical music"?

Lacking the 50-year-plus hindsight advantage of a contemporary jazz or blues scholar, I have decided to discuss the DJ as a composer in autobiographical fashion. Having observed DJs close-up in many settings for more than a decade, ${ }^{3}$ I have attempted to learn how to make music in DJspecific ways by emulating those I studied, both in performance settings where observation was the prime method of investigation, and in formal and informal verbal exchanges where analytical and reflexive approaches amplified and fleshed out the behavior displayed in performance. Using Mantle Hood's concept of bi-musicality (1971) as an inspiration, this process included the acquisition of DJ technology, techniques, and repertoires early on, and has, spanning several years, involved me in practicing 
various types of mixing and programming in both private and, more recently, public settings. The question of how a DJ composes is thus related to the question of how I, a formally trained jazz composer, became a composing DJ.

In New York, beginning in 1991, I entered DJ school. It was not a formal institution, but a school nonetheless. In my quest to better understand contemporary dance music, I was no longer content with merely collecting, or with listening and dancing to various kinds of dance music on record, such as hip-hop, house, disco, and reggae dancehall. Instead, I wanted to learn how to use the music on these records like a DJ, to better understand how DJs conceptualized music, dancing, and the relationship between the two. The method used to accomplish this was similar to the way musicians learn from their elders in many cultures around the world: by observing, witnessing, and emulating over long stretches of time-the way sons learn from their fathers. ${ }^{4}$ Whenever I now program dance music at various kinds of establishments around New York City, I use the following considerations to select and organize the records I will use in performance.

1. How familiar will the audience be with a song? Drawing in an audience that came to dance means using music to which that audience can relate. Playing too much unfamiliar repertoire may be counterproductive.

2. How long have I owned the record? Does it still (or again) excite me? How long has it been since I last played it? How did my audience react then?

3. Does the record fit with others particularly well? It seems that certain records go well with certain others; I often learn this from listening to other DJs. Some records tend to form groups, by relating stylistically, thematically, or texturally to each other. Others have similar instrumentation, hooks, or voices, or share recognizable samples, phrases, or sounds.

4. Will the record add variety or monotony to the mix? With respect to the entire set of music, does the record keep, raise, or lower the musical energy level?

5. Will others in the audience be likely to be curious about the record, either because it's new or because it hasn't been played for a while?

6. Is the record in good condition? How will it sound on the PA system I will be using? What steps are necessary to ensure that it sounds as good as the previous or next record?

In addition to these considerations, composing dance music at a club involves the following in-the-moment decisions, which may be familiar to the improvising jazz musician:

1. How long should the record play? Is the audience getting more or less excited while the record is played through the sound system? 
2. Is the texture "interesting" enough? Is the energy of one record compatible with that of the previous one(s) and/or the one(s) I want to play next? Let me consider texture, tempo, and maybe the key or mode.

3. What is the story I'm telling? To whom am I directing the music, the song? Whom am I trying to affect or move with the way I am putting together the music program?

4. How am I telling the story? What expressive means do I have at my disposal to be as compelling a storyteller behind the turntables as is possible? In other words, how do I compose as a DJ?

For the past thirty years or so, club deejaying has been an oral tradition, passed down from one generation of DJs to the next, with some DJs establishing themselves as more influential than others, becoming true master DJs in the process. Of all New York DJs, arguably the most influential DJ was Larry Levan. To this day, he is revered and remembered as the epitome of what a club DJ should be. The example he set in the DJ booth at Paradise Garage, a club that was open from 1976-1987 in lower Manhattan, is still held up as the one to aspire to, almost a decade after his death in 1992. As such, Levan is perhaps the ultimate DJ teacher.

What did someone like Larry Levan impart to his students? Having spoken to many of them, I'd like to suggest that he taught other DJs to compose. Rather than using the word "composition," however, he spoke of "telling a story with records," something he had learned from Nicky Siano at Gallery in the mid-1970s. Telling a story with records is a particular application of what others have called "programming," that is, choosing a certain quality and sequence of recordings which, when strung together in particular ways during a night of dancing, impart a sense of extreme satisfaction to those witnessing the performance, particularly the dancers. Composing in this way means returning to the original meaning of the Latin root: to put together.

On some weekends, Larry Levan's reputation turned Paradise Garage into a DJ seminar as much as a dance club. After a period of more than ten years as a visitor to many dance clubs in New York (and, later, DJ homes), I can say that I had the good fortune of having Larry Levan as the first teacher of many. In hindsight, I believe I had some of the very best in the trade, and it is with a great deal of gratitude that I refer to them individually below.

One thing I noticed was that while these DJs, some of whom now have worldwide acclaim, deejay in very different ways, they tend to use the same turntable model, a sturdy Japanese instrument made by Technics. In 1991, the acquisition of two direct-drive Technics SL-1210 turntables marked the beginning of my DJ apprenticeship. Victor Sanchez showed me where to shop for turntables (including the right needles) without going broke, and how to set them up. From Danny Tenaglia and Kenny Carpenter I 
learned how to organize my growing record collection. From observing Tony Humphries and David DePino, I learned about pacing and programming and what's involved in "peaking a floor." From Basil Thomas I learned how, during programming, to think two records ahead (or more) instead of just one. Kenny Carpenter showed me that a DJ sometimes changes his mind at the last possible moment about which record to play next. From "Little" Louie Vega, David Camacho, and Tyrone Francis I learned about seamless beatmixing, using a so-called lollipop headphone for one ear and a monitor speaker for the other. From listening to David Mancuso and Larry Levan, I learned that beatmixing was not always necessary or desirable. Silences and changes in tempo had their place in a program, too. From Larry Levan and his mentor Nicky Siano I learned that DJs can tell a story by sequencing and mixing records in certain ways. From listening and dancing to Frankie Knuckles and David Mancuso, I learned to respect and use the power of a beautiful song, referred to frequently as a "classic." From Junior Vasquez and DJ Pierre I learned about the hypnotic power of an instrumental track, often lasting more than ten minutes on record and more than fifteen in performance. ${ }^{5}$

From talking to Victor Simonelli, Basil Thomas, Danny Tenaglia, Joaquin "Joe" Claussell, and Danny Krivit, I learned the importance of knowing the repertoire, as well as the stylistic categories used by record company personnel, DJs, and dancers. "Knowing the repertoire" also applied to the history of dance music and to the multiple versions of a song, often released years apart, and on different record labels. From Basil Thomas, Kim Lightfoot, and Ian Friday I learned more about the connections between dance music and other categories of music, such as jazz, soul, Afro-beat, or rock; and I remembered hearing Larry Levan playing British New Wave or German electronic music such as Manuel Göttsching's "E2-E4" at Paradise Garage. Observing Larry Levan, Frankie Knuckles, and David Morales spin at Tar Babies, Sound Factory Bar, and Red Zone, respectively, taught me the pivotal importance of adjusting and fine-tuning a large sound system. From talking to Louie Vega, Victor Simonelli, and Frankie Knuckles, I learned about the connection between playing and remixing records. David Lozada and Eric Clark advised me on how to select and pack records for upcoming DJ gigs. By observing Timmy Regisford and Joe Claussell I found out how certain records can be enhanced dramatically by using a three-way crossover unit.

Watching Kenny Carpenter and André Collins work, I learned that some, but not all, DJs dance in the DJ booth. Jeffrey Allen showed me how DJs play alongside musicians when he invited me to play guitar alongside his mix in the DJ booth at Limelight one night; from Louie Vega and Roger Sanchez I learned that some DJs play other musical instruments, such as Latin percussion or the piano. Tony Humphries and Johnny 
Dynell taught me about the importance of humor in deejaying, and from talking with David Mancuso, David Lozada, and Francis Grasso, I learned about the pain of losing records through theft or fire.

Frankie Knuckles told me how, during the 1970s, he had learned some deejaying fundamentals from Nicky Siano, at Gallery. At the end of the conversation, he smiled and said, "Welcome to the family!"- thereby establishing, without naming it as such, the context in which we were talking: DJ school.

Subjectively speaking, graduation day at this school is far away. I consider myself barely an upperclassman and, at least at the time of this writing, tend to treat the questions and concerns addressed above as an ongoing process. Each deejaying experience, each exposure to a new record can offer a new perspective, a partial answer to a still open question. As is true of many other musical roads, this has certainly been an exciting one to travel. To those who say that every note has been sounded, every combination has been tried, and every aesthetic musical statement has been put forth, I say, "Try composing as a DJ for a while and see if you change your mind."

\section{Notes}

1. For a detailed discussion of clubbing, see Malbon (1999).

2. Note that here I am not considering the comparatively longer history of the radio DJ, as detailed by Passman (1971) and Poschardt (1998).

3. The results of those efforts are published in Fikentscher (2000).

4. DJ Larry Levan was given the nickname "The Father" because he influenced so many younger acolytes who would come to his club, Paradise Garage, not to dance but to observe him at work in his DJ booth.

5. Extending the length of a record is accomplished by overlapping the playing of two copies of the same record on two turntables.

\section{References}

Fikentscher, Kai. 2000. "You Better Work!" Underground Dance Music in New York City. Hanover, NH: Wesleyan University Press/University Press of New England.

Hood, Mantle. [1971] 1982. The Ethnomusicologist. Kent State University Press.

Malbon, Ben. 1999. Clubbing: Dancing, Ecstasy and Vitality. London \& New York: Routledge.

McClary, Susan. 1985. The Politics of Silence and Sound. In Noise: The Political Economy of Music, 149-58. By Jacques Attali. Minneapolis: University of Minnesota Press. Epigraph from page 156.

Passman, Arnold. 1971. The Deejays. New York: Macmillan.

Poschardt, Ulf. 1998. DJ Culture. London: Quartet.

Westbam (mit Rainald Goetz). 1997. Was ist Record Art? In Mix, Cuts $\mathcal{E}^{2}$ Scratches. Berlin: Merve Verlag. Epigraph: "Record Art is, kurz gesagt, ein Komponieren neuer Stücke anhand vorhandener Platten." Author's translation. 